\title{
Management Innovation and Practice of Full Life Circle in Offshore Petroleum Exploration Target
}

\author{
Jin Liao, Yunzhi Jin, Xunda Wu, Hao Liang* \\ CNOOC China Ltd.-Zhanjiang, Zhanjiang, China \\ Email: ^1248541271@qq.com
}

How to cite this paper: Liao, J., Jin, Y.Z., $\mathrm{Wu}$, X.D. and Liang, H. (2018) Management Innovation and Practice of Full Life Circle in Offshore Petroleum Exploration Target. International Journal of Geosciences, 9, 371-378.

https://doi.org/10.4236/ijg.2018.96023

Received: June 1, 2018

Accepted: June 24, 2018

Published: June 27, 2018

Copyright (c) 2018 by authors and Scientific Research Publishing Inc. This work is licensed under the Creative Commons Attribution International License (CC BY 4.0).

http://creativecommons.org/licenses/by/4.0/

\begin{abstract}
Faced with the continued downturn of international oil price and increasing complexity of oil-gas geological conditions since 2013, CNOOC China Ltd., Zhanjiang has promoted management innovation of full life circle with the theme of "value to exploration-oriented", establishing QC system of multiple-dimension exploration to make exploration target management standardized and institutionalized, putting forward new ideas, closed-loop management of "big data" in full life circle to make exploration target and decision flow informationized, generating comprehensive reserve method of exploration target optimization and quantifiable management mode of "probabilistic method" evaluated by experts, and establishing "optimal solution" to management decision model to manage optimal target combination to drill and bring about lean management of exploration deployment. All the management innovations and practices have been carried out in oilfields of western South China Sea successfully, with corporation's exploration decision and deployment guided effectively, a great success of petroleum exploration, and remarkable economic as well as society benefits.
\end{abstract}

\section{Keywords}

Offshore, Petroleum Exploration, Full Life Circle, Management Innovation, Multiple Dimensions, Big Data

\section{Introduction}

The South China Sea is rich in oil and gas resources, known as the second Persian gulf [1]. Compared with onshore, offshore oil and gas exploration requires higher input, risk and technical requirements, so how to improve the success 
rate of exploration by management innovation is always the goal that CNOOC has been pursuing [2] [3]. With the improvement of exploration in recent years, three tends and characteristics have become increasingly clear for oil and gas exploration in South China Sea: 1) exploration strata is gradually changing from mid-shallow to mid-deep; 2) water depth in exploration region is increasing from shallow to deep; 3) trap exploration is gradually changing from structural traps to lithological traps. Faced with the increasing complexity of oil-gas geological conditions, many problems during exploration target management have come up: 1) exploration target management cannot reach the expected effect due to short of scientific ideas, effective tool and perfect data; 2) the scope, content and method of document management in traditional exploration target are very limited and short of scientific deployment decision based on "big data"; 3) traditional exploration target is mainly qualitative, short of advanced ideas and reliable tool to support scientific quantitatively assess; 4) traditional study of exploration target aims at geological tasks without value guidance.

Facing with the impact of low oil price and complex geological conditions in the western South China Sea, such as high temperatures and pressures, deep water, low porosity and permeability, CNOOC China Ltd.-Zhanjiang has switched mindset and expanded the mind of oil and gas exploration, put forward "management effectiveness" and creatively carried out management innovation of full life circle guided by valuable exploration [4] [5] [6]. Under the management innovation since 2013, 300 billion cubic meters of natural gas reserves have been discovered in deep water area with high temperatures and pressures, success rate of exploration and indexes (reserves addition, decline in barrel oil costs, reserve and production ratio) have been improved greatly which gain remarkable economic as well as society benefits. The main methods and achievements of the innovation will be elaborated in this paper.

\section{QC System of Multiple-Dimension Exploration Target Study}

Returns ratio of exploration activity can be affected by many factors, but the primary is research quality of exploration target, so multiple-dimension QC system is put forward to enhance research level and ensure the quality of research results. Based on "precise, detailed, intensive and actual" standards and core ideas, "emphasis on prevention, process control and sustain improvement", organization systematization, behavior standardization and programmed decision can be achieved, attaining the management objective of clarifying responsibilities and QC progress and comprehensively promoting exploration management upgraded and benefit increased.

\section{1. "Three Vertical and Three Horizontal" QC System of Exploration Target Study}

To ensuring the quality of exploration target study, each management processes of well review is under constant refinement and quantification, and responsibil- 
ity is shared by everyone, generating "three-level quality control and review system" which is carried out on process quality control of well study, making various risk factors under effective control and forming working atmosphere where everyone knows, stresses and guarantees quality. Review and quality control in three different levels support and supplement each other, revolve the subject of "quality" and make maximum ensurance of research quality of warehousing target.

\subsection{Quality Control Content of "Five Sets and Thirty Items"}

Faced with complex geological conditions, such as high temperature and ultrahigh pressure, deep to ultra-deepwater, deepwater and high pressure, complex lithologic stratigraphic trap, deep low porosity and permeability, deepening well study can be the code turning stone into gold in complex exploration areas, with anintegrated research process that exploration project research as domination and major project as technical support. Besides, refined quality control is adopted, as much as possible, to ensure the quality of well study. Besides, comprehensively considering the geological condition and economy, QC expert groups are subdivided into 5 sets of sedimentary reservoir, geochemistry and accumulation, structural trap, reservoir prediction and hydrocarbon detection, and economic assessment, and QC contents are subdivided into thirty items. The QC contents of "five sets and thirty items" are heavily intertwined and in reciprocal causation, and new sparks of thought are constantly being created under the assessment and communication by experts in various fields, helping researchers consider and assess all sides, better promote the progress of well study and improve study quality remarkably.

\section{Closed-Loop Management of Big Data in Full Life Circle of Exploration Target}

To manage the achievements of exploration targets from stages of research, review, warehousing, drill-up and post-drilling assessment, and fully exploit the potential value of big data, the closed-loop management mode of big data in full life circle of exploration target is put forward:

1) Various posts, such as exploration target research, data acquisition, QC, expert review, leadership decision, warehousing stock, preferential queen, portfolio optimization, post-drilling assessment and expert review, are under management by closed-loop management mode (Figure 1);

2) Object-oriented business and data model of exploration targets is established for the analytical data flow by advanced information technology, realizing integration of exploration and development database model;

3) Foundation database of exploration targets is established to manage the basic information, action implementation, evaluation information, audit situation, prospecting well design, drilling progress and result data, including geological information, exploration target organization and dynamic state, data assessment, drilling data, definition of data type, data information and GIS query, standard 


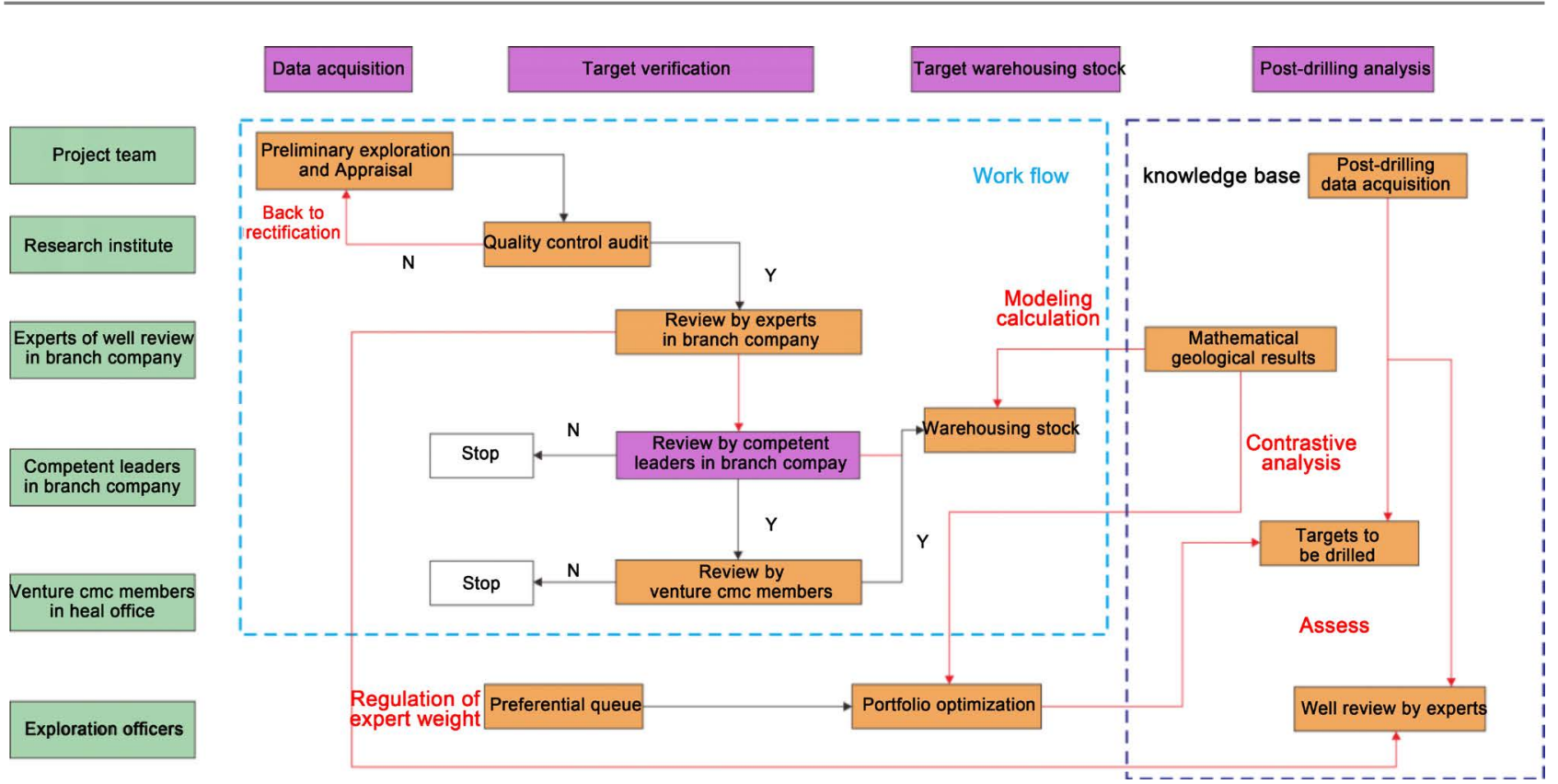

Figure 1. Data flowchart of full life circle in exploration targets.

specification management, product submission specification, audit content, statistic analysis, history view and result management of exploration targets, specification report and Atlas production, finally to realize electronic management of basic and result data of exploration targets;

4) Based on data model of PPDM and POSC and advanced data synchronization technology, big data of exploration target and expert repository of target review are established, enhancing accumulation of explicit and tacit knowledge. With full exploitation of values from big data and repository, knowledge of quantitative evaluation on exploration target from various zones, bed series and reservoir types, is continuously enriched, laying the foundation of intelligent decision of value exploration orientation.

\section{Optimization of Exploration Targets and Quantitative Management of Expert Review}

\subsection{Optimization of Exploration Targets by Integrated Reserve Method}

One of the important tasks during exploration management is to lining up the targets according to factors of warehousing exploration targets. The traditional target line based on reserve indicator, such as potential geological reserve and recoverable reserve, is limited [7] [8] [9] [10] [11]. As a result, by considering the mutually constrained parameters including the geological conditions, field properties, hydrocarbon types and expert mark, and dual character of return-risk, primary economic assessment indicators (internal rate of return, payback period, etc.) and risk assessment indexes (economic risk, engineering risk, etc.) are chosen as the primary assessment indexes to establish integrated reserve method applicable to the exploration target optimization in western South China Sea by 
optimization and permutation of a series of geological parameters. The method is expressed as the follows:

$$
A(f)=((1-R) \times L) \times((1-R) \times C / 0.12) \times W \times A
$$

In this formula: $\mathrm{A}(\mathrm{f})$-integrated reserve scale; $\mathrm{R}$-risk factor, \%; C-yield rate, \%; L-field coefficient, $\mathrm{L}($ oil $)=1+(\mathrm{A}-1000) /(10,000-1000), \mathrm{L}(\mathrm{gas})=1+(\mathrm{A}-$ $100) /(1000-100)$; W-coefficient of well control reserve, \%; A-reserves size, $10^{4}$ $\mathrm{m}^{3}$ (oil equivalent).

\subsection{Probability Method of Expert Quantitative Evaluation}

Management, assessment and review by exploration experts are the extension of exploration target management. Probability method can establish a standard system of assessment and review by exploration experts. Total expert score is obtained based on oil-gas possibility, expert attendance and single-objective score by counting single-objective score according to matching degree between post-drilling results and pre-drilling expert grading in advance, realizing change of expert review from qualitative to quantitative assessment. As showed in Table 1 , if the success rate of exploration targets is $20 \%$, target optimization gets approved only two thirds of experts expressing their agreement. The total score is calculated based on scores of single target by experts and actual drilling results (Table 2). According to the assessment result, the exploration expert repository is constantly improved, and rating weight by exploration expert is under dynamic regulation, generating closed-loop feedback mechanism between exploration expert review and weight and improving reliability of exploratory decision.

\section{Management Decision Model of Optimal Solution during Exploration Deployments}

Foothold of value exploration is the management of exploration portfolio and its

Table 1. Existing probability analysis by experts.

\begin{tabular}{cccccc}
\hline Category & \multicolumn{2}{c}{ Situation1 Probability1 } & Situation2 Probability2 & \multicolumn{2}{c}{ Notes } \\
\hline Oil-gas possibility & yes & $20 \%$ & no & $80 \%$ & Exploration success ratio of 20\% \\
Appraisal results & agreed & $66.67 \%$ & disagreed & $33.33 \%$ & $\begin{array}{c}\text { Passed only with agreement } \\
\text { by two-thirds majorities }\end{array}$ \\
\hline
\end{tabular}

Table 2. Score analysis of single target.

\begin{tabular}{ccccccc}
\hline Situations & $\begin{array}{c}\text { Expert } \\
\text { opinion }\end{array}$ & $\begin{array}{c}\text { Drilling } \\
\text { results }\end{array}$ & $\begin{array}{c}\text { Initial } \\
\text { score } \\
(\mathrm{a})\end{array}$ & $\begin{array}{c}\text { Pass rate } \\
(\mathrm{p}=\text { approved } \\
\text { number/headcount })\end{array}$ & $\begin{array}{c}\text { Final score } \\
\mathrm{a} /(\mathrm{p} /(2 / 3) * 0.8)\end{array}$ & $\begin{array}{c}\text { Final } \\
\text { interval }\end{array}$ \\
\hline 1 & agreed & yes & 100 & $100 \%$ & 83 & $83-100$ \\
2 & agreed & no & 55 & $100 \%$ & 66 & $55-66$ \\
3 & disagreed & no & 80 & $95 \%$ & 91 & $80-91$ \\
4 & disagreed & yes & 20 & $95 \%$ & 18 & $18-20$ \\
\hline
\end{tabular}


core is to maximize reserves with minimal investment. By continually exploring and researching and application of mathematical geological method, solving models of portfolio optimization controlled by various factors are established which aim at maximizing reserves with minimal investment. Factors of model selection include total fixed investment and rig resources:

1) Solution logic of total investment planning (Figure 2): constraint conditions are $\mathrm{A} / \mathrm{B} / \mathrm{C}$ integrated reserve data, $\mathrm{A} / \mathrm{B} / \mathrm{C}$ target single well cost $\left(10^{4} \mathrm{yu}-\right.$ an), total investment $\left(10^{4}\right.$ yuan), proportion of prospecting wells in various field $(\operatorname{SUM}($ actual $)=55 \%-65 \%, \operatorname{SUM}($ rolling $)=15 \%-25 \%, \operatorname{SUM}($ new frontier $)=$ $15 \%-25 \%$ ) and proportion of well types (oil/gas prospecting well types, proportion of shallow/deep water (optional)).

Solve the maximum value of integrated reserve when total investment $I(t)$ under the same conditions, in order to obtain optimized drilling target combination.

Total fixed investment: after input of drilling targets, requirement of different wells can be practicable (rigs per unity month) according to parameters of drilling targets.

2) Solution logic of rig resources and fixed planning: constraint conditions are the same with those in 1), and find maximum value of integrated reserve under invariant rig resources in order to obtain optimized drilling target combination.

The solving model will automatch the optimal constraint boundary value according to variation of constraint parameters in big data base and achieve dynamic solution based on real-time data.

\section{Achieved Results}

Since 2013 new management ideas and methods of exploration targets have been applied, making breakthroughs in medium-deep and high-temperature and

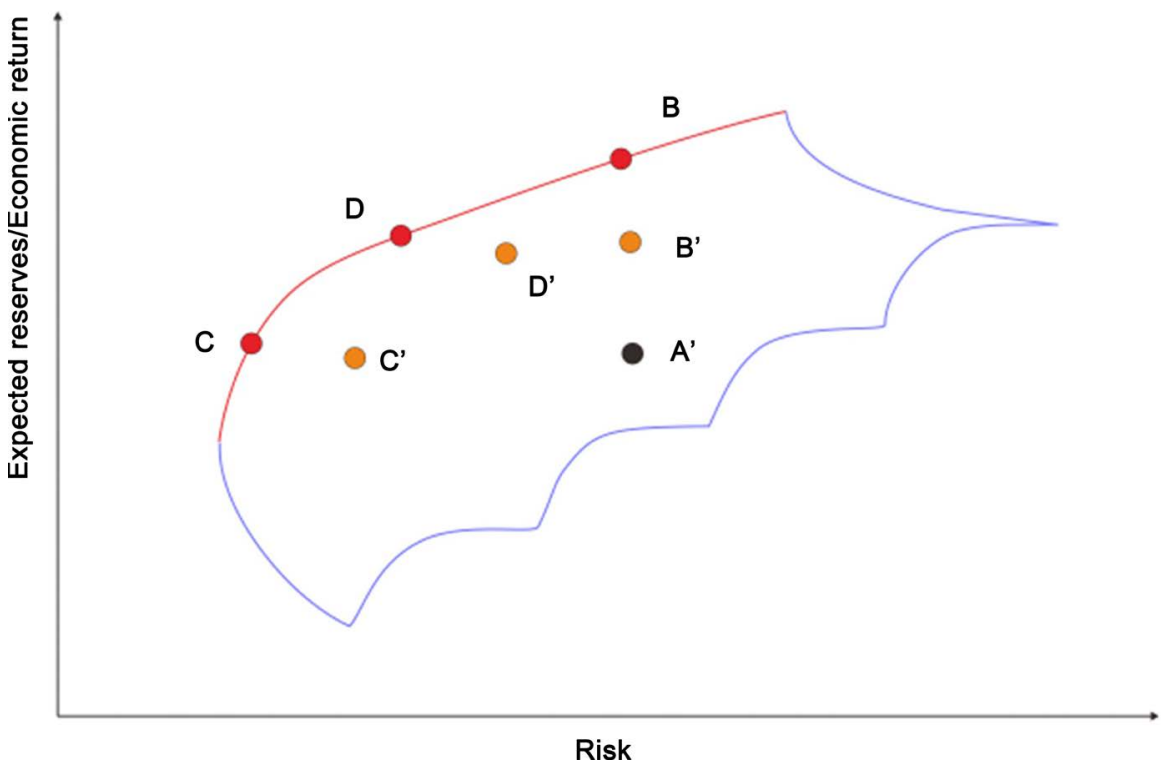

Figure 2. Solution logic of total investment planning. 
pressure Yinggehai basin and deepwater areas in Qiongdongnan basin, with the East 13-2 high-temperature and pressure gas field bearing a hundred of billions of cubic meters of natural gas, Lingshui 17-2, 18-1 and 25-1 deepwater gas fields bearing two hundreds of billions of cubic meters of natural gas consecutively been discovered. By refined management, rolling explorationis carried out to search for high-quality substitute reserve, realizing output continuously increased for five consecutive years in Weixinan depression and keeping in high level with yearly output up to two million tons. Since 2014 the average exploration success ratio is up to $81 \%$, increased by $14 \%$, average new added recoverable reserves has increased by $206 \%$, average barrel of oil cost has decreased by $21.6 \%$, reserve and production ratio of gas fields has been improved continually, with the ratio of oil and gas up to 22 and that of gas fields up to 44 . By continuous innovation and practice, western South China Sea have been qualified to be gas fields with trillion of cubic meters of natural gas.

Deeper integration between management and technology, transformation and innovation of management ideas driven by informationization, have realized scientific and professional management, established evaluation formworks appropriate for every exploration region. Optimization of evaluation algorithm, integration of expertise, optimization of lining-up targets and investment portfolio have supply stable big data support for scientific deployment decision of exploration target guided by value of exploration.

\section{Conclusion}

Through perennial innovation and practice of full life circle for exploration targets, multiple-dimension QC system, guided by value of exploration and the method of information, has been established in western South China Sea, effectively promoting standardization and institutionalization of exploration target management; closed-loop management of big data in full life circle of exploration target has been put forward, realizing informatization of target management and decision flow; optimization system of integrated reserve method of exploration targets and probability method of expert quantitative evaluation have been established, realizing target optimization dominated by quantitative assessment and management mode of expert review; management decision model of optimal solution during exploration deployments has been established, managing optimized drilling target combination, comprehensively improving oil and gas exploration results and promoting lean management of exploration and deployment. All above innovation and practice in oil fields in western South China Sea have been successfully carried out, effectively guiding exploration decisions and deployment, remarkably improving oil and gas exploration results, such as gas reserves bearing hundreds of billions of cubic meters of natural gas in medium-deep and high-temperature and pressure Yinggehai basin and deepwater areas in Qiongdongnan basin, and gaining remarkable economic as well as society benefits, which are available for reference for other sea areas. 


\section{References}

[1] Xie, Y.H. (2015) Status and Prospect of Proprietary Oil and Gas Field Exploration and Development in Deepwater West Area of South China Sea. Oil Drilling \& Production Technology, 37, 11-13.

[2] Xie, Y.H. (2014) A Major Breakthrough in Deepwater Natural Gas Exploration in a Self-Run Oil/Gas Field in the Northern South China Sea and Its Enlightenment. Natural Gas Industry, 34, 1-8.

[3] Wu, M.W., Yang, H.J., Liang, H., et al. (2015) Key Techniques and Practices of Critical Flow Based Tests for Deepwater Exploration Wells: A Case Study of Deepwater Area in the Qiongdongnan Basin. Natural Gas Industry, 35, 65-70.

[4] Xu, X.H., Cai, L.X., Liu, C.Y., et al. (2015) Evaluation and Selection System for Petroleum Exploration Targets. Oil \& Gas Geology, 36, 517-524.

[5] Cai, L.X., Yan, X.B., Li, N., et al. (2014) Evaluation, optimization and decision system for prospects to drill. Oil \& Gas Geology, 35, 720-728.

[6] Guo, Q.L. and Mi, S.Y. (2004) Assessment of Petroleum Exploration Target and Decisions. Petroleum Industry Press, Beijing, 21-22.

[7] Guo, Q.L. and Mi, S.Y. (2004) Assessment of Petroleum Exploration Target and Exploration Decisions. Petroleum Industry Press, Beijing, 150-206.

[8] Yin, A.Z. and Zhang, M. (2010) Analysis of Oil Production Market Structure and Producer Behavior Game. Journal of Southwest Petroleum University (Social Science Edition), 3, 10-14.

[9] Guo, Q.L., Zhai, G.M. and Shi, G.R. (2004) Improved Model and Related Methods for Integrative Evaluation of Plays. Acta Petrolei Sinica, 25, 7-11, 18.

[10] Xie, Y.F., Chen, H.P., Ma, Z.Z., et al. (2014) Probabilistic Estimation of Reserves and Difference between Probabilistic and Determine Methods. Petroleum Geology \& Experiment, 36, 117-122.

[11] Jia, C.Z., Yang, S.F., Zhang, Y.F., et al. (2004) Risk Analysis and Economic Valuation of Oil and Gas Exploration Project with Real Option Method. Petroleum Industry Press, Beijing, 76-79. 